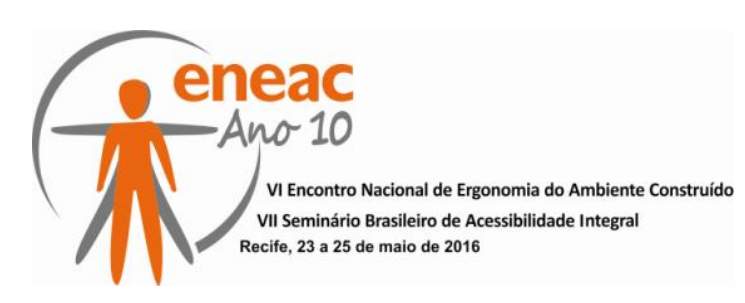

\title{
AVALIAÇÃO DOS PARÂMETROS ARQUITETÔNICOS DE ACESSIBILIDADE E MOBILIDADE DE UM HOSPITAL FILANTRÓPICO NA PERSPECTIVA DOS PACIENTES
}

\author{
KATO, Mayla Youko (1); \\ MÜLFARTH, Roberta Consentino Kronka (2) \\ (1) Faculdade de Arquitetura e Urbanismo FAUUSP, Mestranda \\ e-mail: maylakato@outlook.com \\ (2) Faculdade de Arquitetura e Urbanismo FAUUSP, Doutora \\ e-mail: rkronka@usp.br
}

\begin{abstract}
RESUMO
O presente artigo avaliou as condições de acessibilidade e mobilidade de um hospital filantrópico de São Paulo. Com o objetivo de verificar e avaliar os parâmetros de adequação das áreas comuns utilizadas pelos pacientes, com foco na acessibilidade e mobilidade. Foram realizados métodos diferentes para esta avaliação, sendo: walkthrough, questionário e check lists que possibilitaram o levantamento dos aspectos positivos e negativos da edificação. Comparando os resultados obtidos foi possível avaliar as condições de acessibilidade e mobilidade do local. A realização desta pesquisa trará contribuições para o alcance da qualidade do espaço do hospital, refletindo o desempenho e qualidade arquitetônica.
\end{abstract}

Palavras chave: acessibilidade; mobilidade; arquitetura hospitalar.

\section{ABSTRACT (11 PTS, NEGRITO)}

This paper evaluated the accessibility and mobility of a philanthropic hospital in Sao Paulo. The objective was to verify and to evaluate the adequacy parameters of the common areas used by patients, focusing on accessibility and mobility. There were performed methods for this assessment and applied the walkthrough, a questionnaire and checklists to evaluate the positive and negative aspects of the building. By comparing the results it was possible to assess the conditions of accessibility and mobility of the site. This research will bring contributions to the achievement of hospital's space quality, reflecting the performance and the architectural quality.

Keywords: accessibility; mobility; hospital architecture

\section{Introdução:}

De acordo com o Instituto Brasileiro de Geografia e Estatística (IBGE), as mudanças ocorridas a partir da segunda metade do século XX levaram à modificação da estrutura etária da população brasileira, com o estreitamento da base da pirâmide e 0 alargamento do topo, em função da diminuição das taxas de fecundidade e de mortalidade (IBGE, 2008).

Em decorrência do acelerado processo de envelhecimento populacional brasileiro, observa-se grandes mudanças econômicas e sociais, como: aumento de gastos previdenciários, aumento de gastos com o sistema de saúde, intergeracionalidade, idosos 


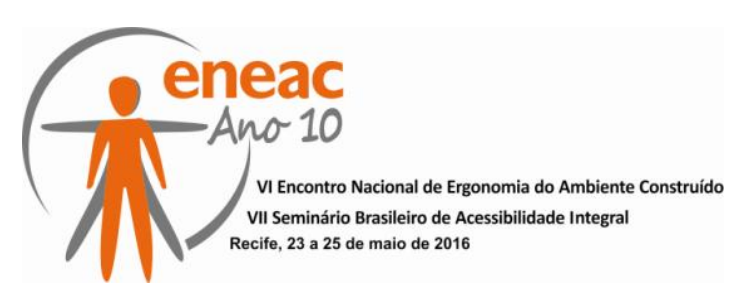

mais debilitados e fragilizados. Nessa abordagem, fazem-se necessárias adequações à arquitetura das instituições hospitalares que assistem idosos com mobilidade reduzida, com o intuito de identificar problemas de acessibilidade hospitalar, e criar propostas e soluções para que o idoso seja atendido de forma mais humana e igualitária.

Destaca-se nesse momento, a importância do projeto arquitetônico para atender esse novo perfil de pacientes, que utilizam os hospitais brasileiros este fato é observado não só nas novas edificações, mas também nas adaptações realizadas em edifícios existentes.

Para Sampaio (2005) os ambientes hospitalares exigem uma atenção maior em relação ao conforto e qualidade, o que favorecerá a adequação dos equipamentos médicohospitalares, a satisfação dos usuários e ainda, a satisfação dos profissionais que atuam nos hospitais.

Nessa perspectiva é importante destacar o conceito de acessibilidade e mobilidade. A acessibilidade é a garantia e a possibilidade de acesso de qualquer ambiente ou objeto a qualquer pessoa. A Acessibilidade, definida pela Associação Brasileira de Normas Técnicas como: "Possibilidade e condição de alcance para utilização, com segurança e autonomia, de edificações, espaço, mobiliário e equipamento urbanos" (NBR 9050, 2004).

Mobilidade pode ser sintetizada na comodidade do deslocamento individual dentro do espaço urbano. Trata-se de um conceito múltiplo, que envolve não apenas variáveis físicas e quantitativas, mas também questões sociais, econômicas e políticas (VIANNA JÚNIOR, 2000). Podendo ser definida como, condições necessárias para o deslocamento das pessoas. Ou seja, ter mobilidade é conseguir se locomover com facilidade de um lugar para o outro, independentemente do tipo de veículo utilizado, de vias públicas e da infraestrutura disponível. (SCARINGELLA, 2013).

Mobilidade e acessibilidade são de grande importância para a população idosa em vista de sua participação ativa na sociedade, portanto, a acessibilidade deve ser considerada já no momento da concepção do projeto a ser implantado, respeitando e cumprindo as determinações das leis e normas, e assim, podendo desenvolver e resolver todas as interfaces dos espaços de convívio com os usuários, respeitando as diferenças socioculturais dos atores envolvidos, e desta maneira, evitar os inúmeros erros de projeto provocados pela construção de edificações e equipamentos urbanos que se tornaram grandes barreiras arquitetônicas impedindo, de maneira arbitrária, o acesso dos idosos e deficientes físicos (CORRÊA et. al., 2004).

As diretrizes estabelecidas pela Norma NBR 9050, ainda não são cumpridas em sua totalidade, mesmo sendo adotada como obrigatória pelo Código de Obras dos municípios no qual se encontram (ABATE 2014). É importante ressaltar, que a norma trata os aspectos da acessibilidade de forma global, com enfoque no desenho universal ao estabelecer diretrizes de projeto para pessoas com dificuldades de locomoção, grávidas, pessoas com crianças de colo, idosos, obesos e deficientes visuais. Neste contexto, é importante observar que em alguns casos soluções específicas são necessárias para a segurança e o bem estar do grupo em questão, como é o caso dos idosos (MILANI, 2014).

Em julho de 2015 foi imposta a Lei Brasileira de Inclusão da Pessoa com Deficiência № 13.146 que assegura e promove, em condições de igualdade, o exercício dos direitos e das liberdades fundamentais por pessoa com deficiência, visando à sua inclusão social e cidadania.

Pensando assim, acredita-se que a satisfação do espaço possibilita a criação de valor para o usuário, possibilitando a construção de uma imagem positiva da instituição e, concomitantemente, uma vantagem na interação entre o ambiente e o comportamento das pessoas que usufruem desse espaço favorecendo assim, a qualidade assistencial dos idosos hospitalizados. Desta forma, a realização desta pesquisa trará contribuições para o 


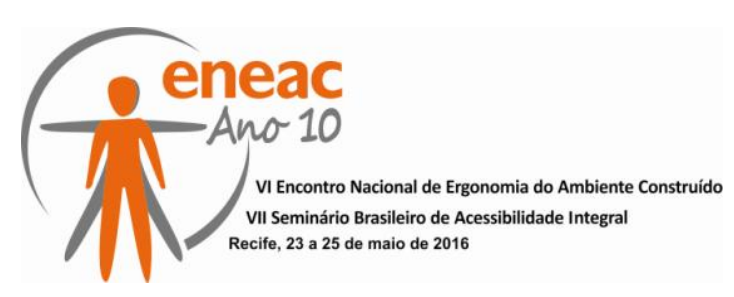

alcance da qualidade do espaço hospitalar, refletindo desempenho e qualidade arquitetônica.

\section{Objetivo:}

Verificar e avaliar os parâmetros de adequação das áreas comuns utilizadas pelos pacientes de um hospital filantrópico, com foco na acessibilidade e mobilidade.

Objetivos específicos:

Avaliar o grau de satisfação dos pacientes internados em uma unidade de atendimento, sobre a acessibilidade e mobilidade hospitalar; Identificar os requisitos de acessibilidade e mobilidade que influenciam no conforto destes pacientes que trabalham em uma unidade de internação hospitalar.

\section{Materiais e métodos:}

A etapa inicial da pesquisa foi composta por estudos teóricos sobre o tema acessibilidade e mobilidade hospitalar por meio de busca literária e visitas em campo.

Estas visitas foram de caráter exploratório que consistem na análise da funcionalidade do ambiente construído, propiciando a indicação dos principais aspectos positivos e negativos do objeto de estudo. Essa primeira coleta de dados in loco ocorreu por meio da aplicação do instrumento walkthrough. No qual foram avaliadas algumas questões de conforto ambiental, como por exemplo, ruído, luz natural, ventilação, entre outros.

O método walkthrough consiste em uma visita dos avaliadores, acompanhados pelos usuários do local ao ambiente de estudo. Durante o percurso os observadores fazem o registo dos pontos levantados por eles e os comentários dos usuários sobre o local, confrontando o olhar técnico com o conhecimento decorrente de sua vivência. (MACHADO et al, 2008).

As visitas exploratórias tiveram como objetivo identificar os requisitos de acessibilidade e mobilidade que influenciaram no conforto de idosos internados em uma unidade de internação hospitalar. Foram realizadas 5 visitas com duração de 2 horas cada. O local visitado foi o edifício hospitalar contendo 11 andares em uma área de $18.445,53 \mathrm{~m}^{2}$. Foi dado prioridade aos 6 andares de internação em que trabalham os profissionais entrevistados.

Na segunda etapa foi aplicado um questionário aos funcionários do local, tendo como base o questionário de Sampaio (2005), que objetiva verificar a percepção, a utilização, a referência e a opinião dos usuários em relação a um determinado produto (ORNSTEIN; ROMÉRO, 1992).

Este questionário foi aplicado em 60 pacientes, estes internados no local de estudo, composto por questões relativas às características socioeconômicas dos respondentes, bem como ao projeto arquitetônico, conforto ambiental, acessibilidade e mobilidade, segurança contra incêndio, tanto do edifício quanto da vizinhança próxima ao mesmo.

A Terceira etapa foi composta pela elaboração e aplicação de um check list, para avaliação de acessibilidade e mobilidade hospitalar, sendo que a etapa inicial colaborou diretamente para o planejamento deste item. Este check list consistiu em um roteiro de levantamento, organizado com base nos espaços existentes e em itens da NBR 9050/2004 (norma em que estabelece critérios e parâmetros técnicos a serem observados quando ao projeto, construção, instalação e adaptação de edificações, mobiliário, espaços e equipamentos urbanos às condições de acessibilidade). E RDC 50/2002 (Regulamento Técnico destinado ao planejamento, programação, elaboração, avaliação e aprovação de projetos físicos de estabelecimentos assistenciais de saúde, a ser observado em todo 


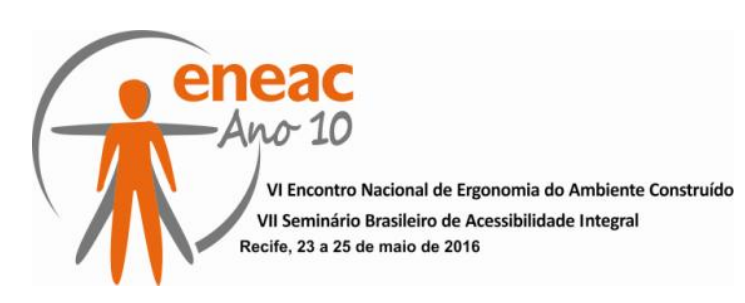

território nacional, na área pública e privada). Durante o levantamento, todos os itens da check list foram fotografados e mapeados, para facilitar identificação e localização dos problemas encontrados.

O check list utilizado neste estudo foi embasado no roteiro elaborado pela Comissão Temporária de Acessibilidade do Conselho Nacional do Ministério Público. O Roteiro Básico para Avaliação da Acessibilidade nas Edificações do Ministério Público visa auxiliar os arquitetos e engenheiros, na implementação da Resolução no 81/2012 do Conselho que dispõe sobre a adequação dos edifícios e serviços às normas de acessibilidade, entre outras providências.

Realizadas estas etapas e tendo sido aplicados os instrumentos, os resultados obtidos foram comparados e interpretados juntamente, gerando um diagnóstico que abrange a identificação de diversos aspectos positivos e de outros a serem melhorados.

\section{Resultados:}

Cabe ressaltar que a participação dos pacientes foi de suma importância para a elaboração deste diagnóstico. Tendo todos os instrumentos aplicados, foram levantadas informações referentes à edificação, abrangendo diversos aspectos.

Os problemas de ordem construtiva constados durante o walktrough, por meio da observação in loco e dos relatos dos usuários foram demostradas no quadro 1.

Quadro 1 - Problemas encontrados no local da pesquisa por meio do método walktrough. São Paulo, 2015.

\begin{tabular}{|c|l|}
\hline Problemas encontrados & \multicolumn{1}{|c|}{ Observações } \\
\hline Rampa de acesso na entrada principal & $\begin{array}{l}\text { A rampa na entrada principal deixa o local não } \\
\text { acessível para as pessoas que possuem } \\
\text { mobilidade reduzida devido a sua inclinação. }\end{array}$ \\
\hline Acessibilidade e mobilidade do sanitário & $\begin{array}{l}\text { Alguns servidores queixaram-se da } \\
\text { acessibilidade e mobilidade dos sanitários. }\end{array}$ \\
\hline Ruídos externos e internos & $\begin{array}{l}\text { Alguns servidores informaram que, no } \\
\text { momento da abertura das janelas nos quartos o } \\
\text { ruído externo incomoda, além das conversas } \\
\text { nos corredores e aviso sonoro do elevador. }\end{array}$ \\
\hline Local para descanso & $\begin{array}{l}\text { Este foi o item que mais obteve respostas } \\
\text { negativas por parte dos entrevistados, pois os } \\
\text { mesmos não possuem local de descanso. }\end{array}$ \\
\hline Cobertura & $\begin{array}{l}\text { Falta de manutenção na cobertura do edifício, } \\
\text { sendo que em alguns lugares foram relatados e } \\
\text { constatados materiais deteriorados. }\end{array}$ \\
\hline
\end{tabular}

Fonte dados de pesquisa 


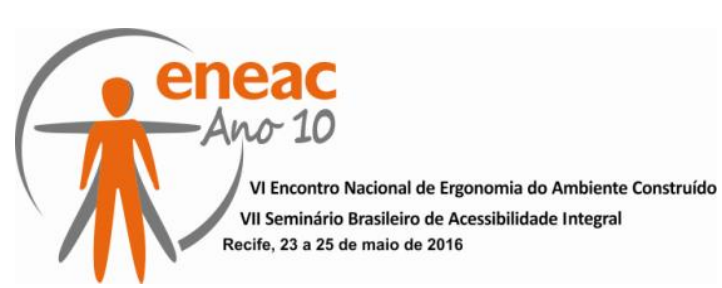

FIGURA 1 - Entrada principal possui rampa com a inclinação maior do que a permitida; com $11 \%$ de inclinação. Falta de manutenção e deterioração da coberta; Banheiro em que não é possível a movimentação de um cadeirante. São Paulo, 2015.
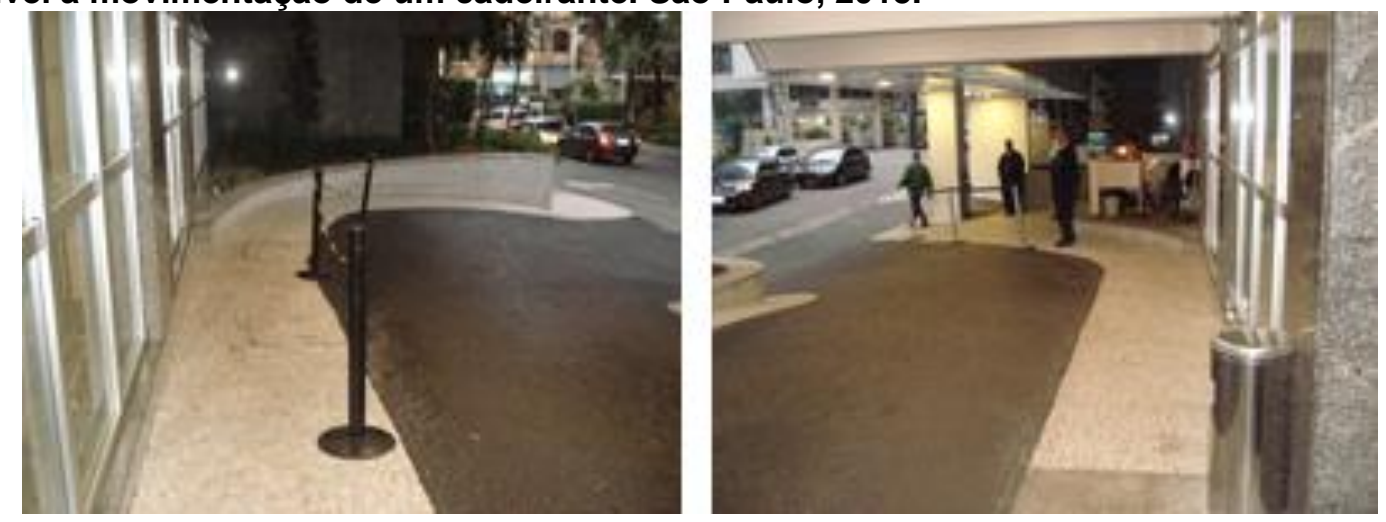

FIGURA 2 - Banheiro com falta de acessibilidade causando impossibilidade de movimentação de um cadeirante. São Paulo, 2015.

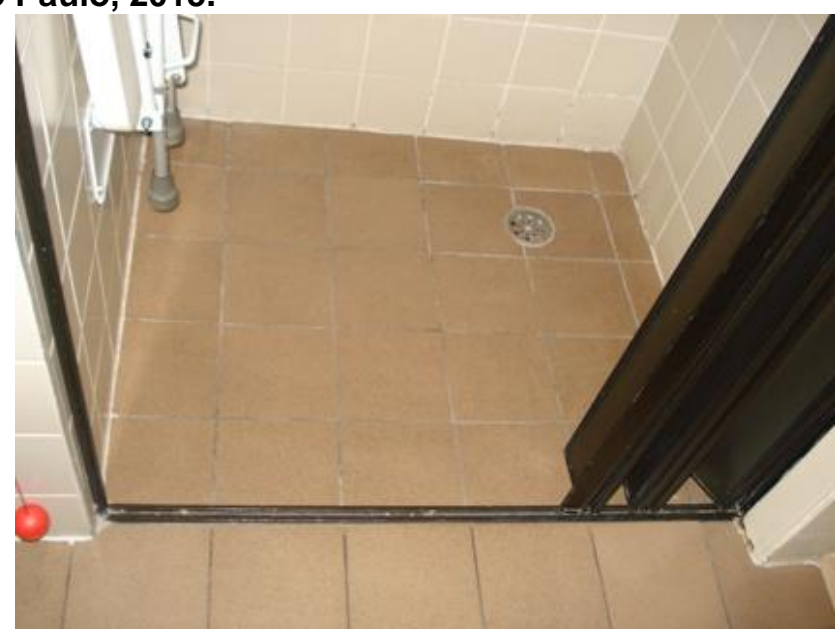

Em relação à aplicação dos questionários, podemos observar no gráfico 1 que o grau de satisfação dos pacientes em relação ao edifício de forma geral, foi considerado muito bom e bom. O item de aparência externa foi o que obteve a pontuação maior seguido de aparência interna e elevadores. 


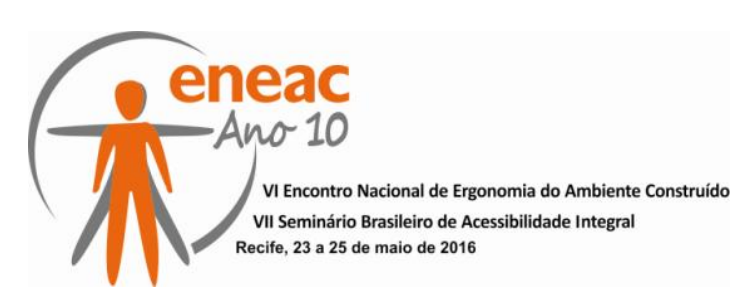

Gráfico 1 - Grau de satisfação dos aspectos gerais do edifício em relação a opinião dos funcionários. São Paulo, 2015.

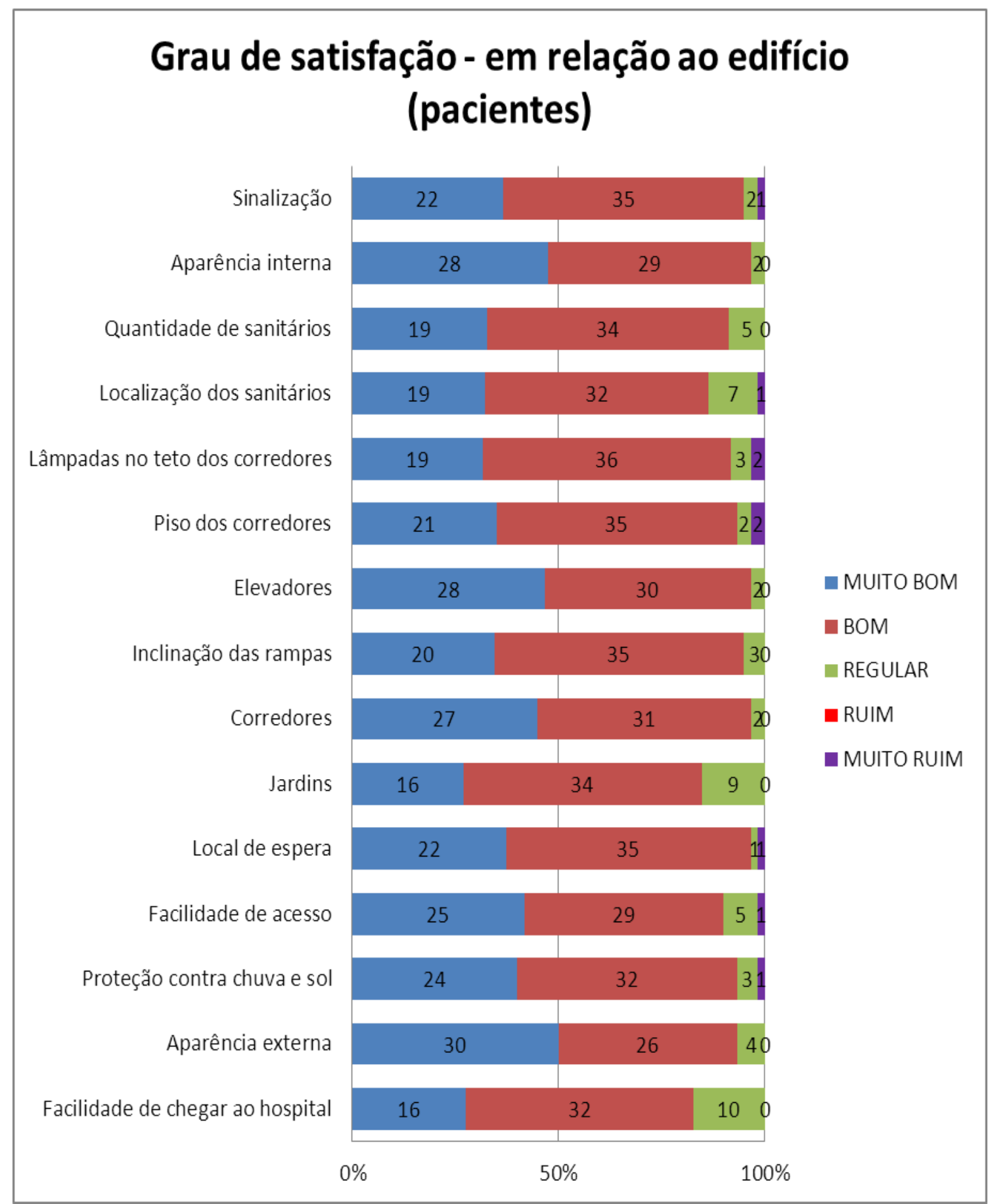

Fonte dados de pesquisa

No gráfico 2 podemos observar a opinião dos pacientes em relação ao local de internação. Novamente as opiniões se demostram positivas, a comunicação com a equipe foi o item mais bem pontuado, seguido do tamanho das janelas. 


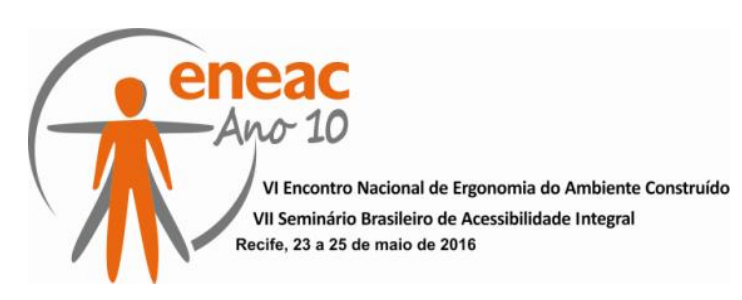

Gráfico 2 - Grau de satisfação do local de trabalho dos funcionários. São Paulo, 2015.

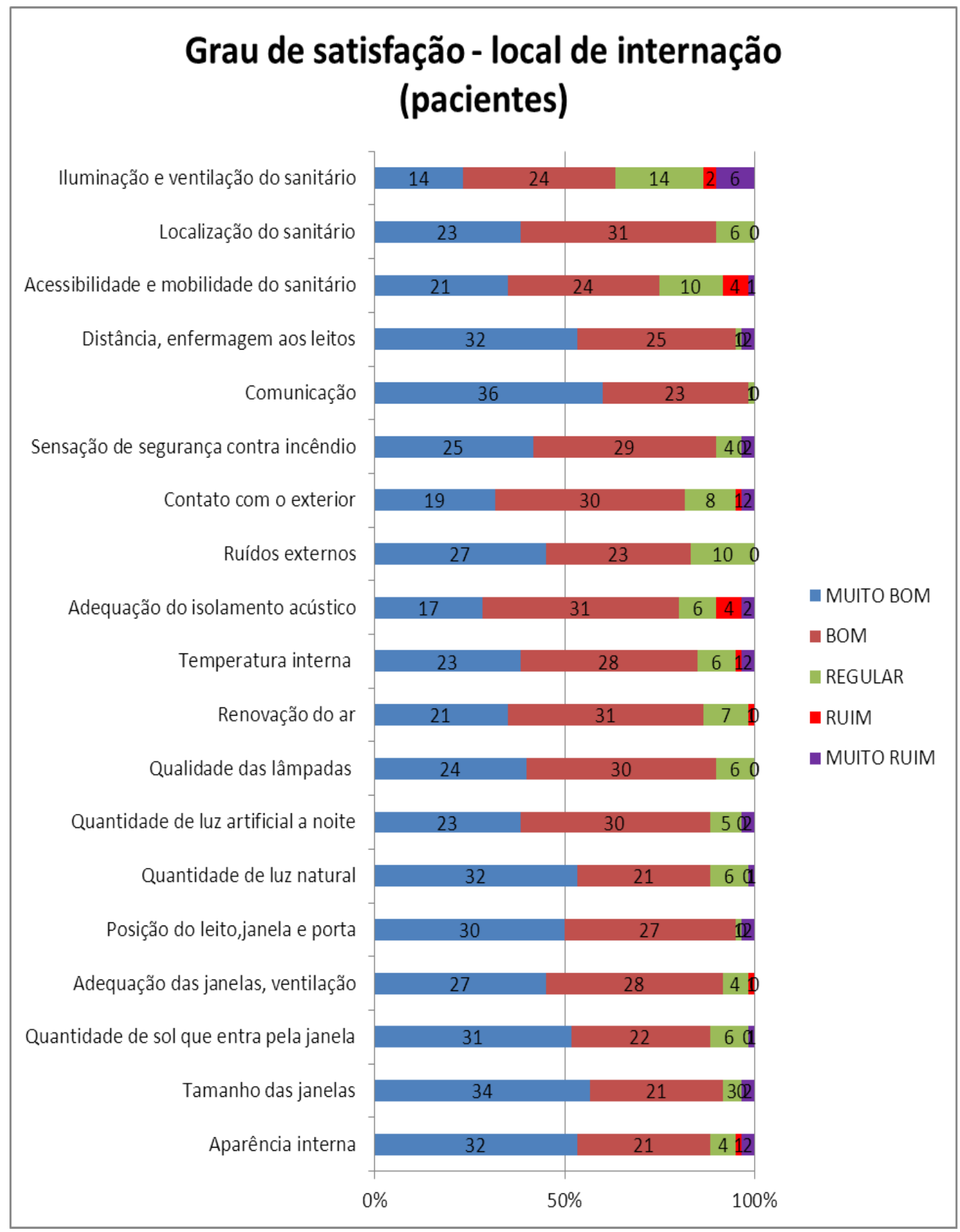

Fonte dados de pesquisa

Foi observado que nenhum item apresentou desempenho insuficiente, o que corrobora com as informações levantadas pelos demais instrumentos, pois apesar da existência de problemas no edifício, a maioria dos usuários encontra-se satisfeito com o 


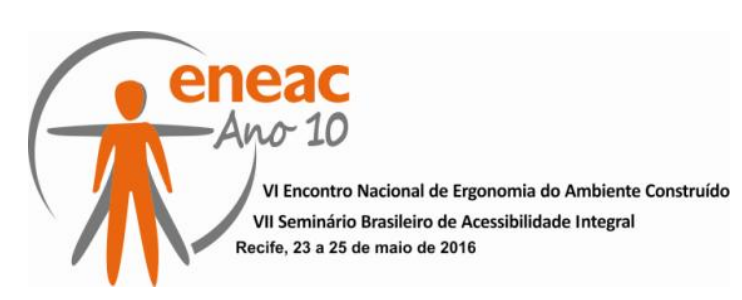

local de trabalho de modo geral. E devido a este ter uma boa localização geográfica e estar localizado próximo à meio de transportes, o acesso foi considerado positivo.

Os aspectos identificados pelos usuários durante as entrevistas foram os mesmos verificados pela pesquisadora durante a aplicação dos diversos instrumentos.

Diante da aplicação do check list de acessibilidade e mobilidade do hospital, as principais deficiências observadas apresentam-se na quadro 2.

Quadro 2 - Problemas encontrados no local da pesquisa por meio do método check list. São Paulo, 2015.

\begin{tabular}{|c|l|}
\hline Problemas encontrados & \multicolumn{1}{c|}{ Observações } \\
\hline Edifício em geral & Ausência de piso tátil direcional e de alerta. \\
\hline Acesso à edificação & $\begin{array}{l}\text { Piso sem superfície antiderrapante, presença } \\
\text { de tapete e falta de sinalização direcional do } \\
\text { acesso da edificação. }\end{array}$ \\
\hline Escadas & $\begin{array}{l}\text { Ausência de piso tátil no início e término das } \\
\text { escadas; falta de sinalização visual na borda } \\
\text { dos degraus. }\end{array}$ \\
\hline $\begin{array}{c}\text { Corredores dos andares de internação } \\
\text { sem ventilação adequada }\end{array}$ & $\begin{array}{l}\text { Falta de ventilação e ar condicionado nos } \\
\text { corredores dos andares de internação. }\end{array}$ \\
\hline Elevadores & $\begin{array}{l}\text { Piso da cabine sem superfície antiderrapante } \\
\text { e sem contraste com o da circulação. }\end{array}$ \\
\hline Sanitários para deficientes físicos & $\begin{array}{l}\text { Apenas um sanitário para deficientes físicos, } \\
\text { localizado no piso térreo do edifício. Sem } \\
\text { dispositivo de sinalização de emergência; } \\
\text { sanitário não acessível. }\end{array}$ \\
\hline Bebedouros & $\begin{array}{l}\text { Os bebedouros encontrados nos andares de } \\
\text { internação estão localizados em uma altura } \\
\text { acima do que é regulamentado. }\end{array}$ \\
\hline
\end{tabular}

Fonte dados de pesquisa

FIGURA 3 - Placa de sinalização dentro do elevador indicando local do banheiro para deficientes. São Paulo, 2015.

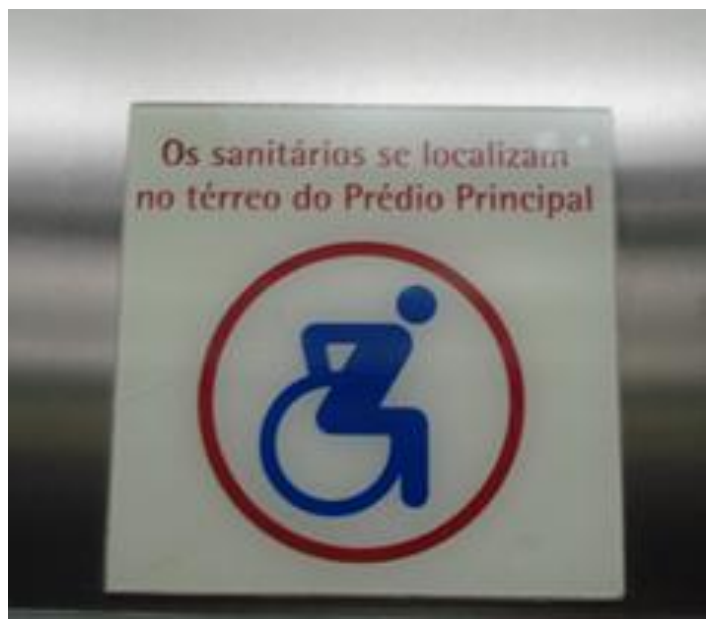




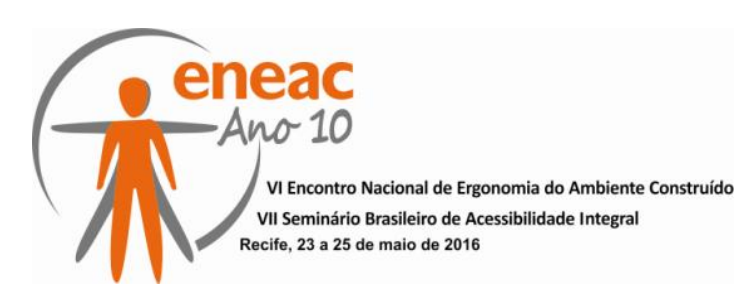

FIGURA 4 - Elevador sem piso tátil (direcional e alerta. São Paulo, 2015.

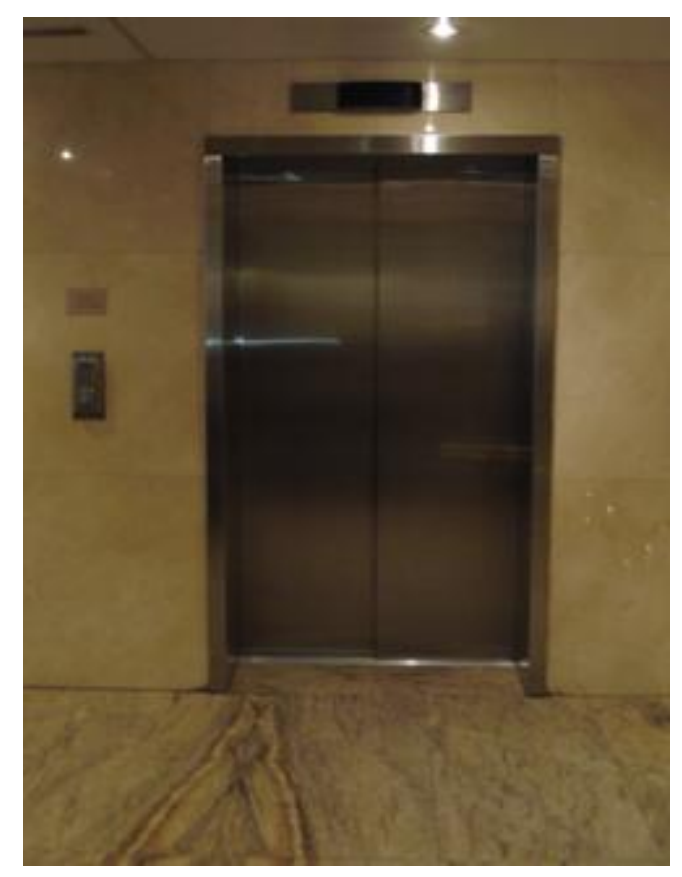

FIGURA 5 - Entrada do hospital sem piso tátil (direcional e alerta) e com tapete. São Paulo, 2015.

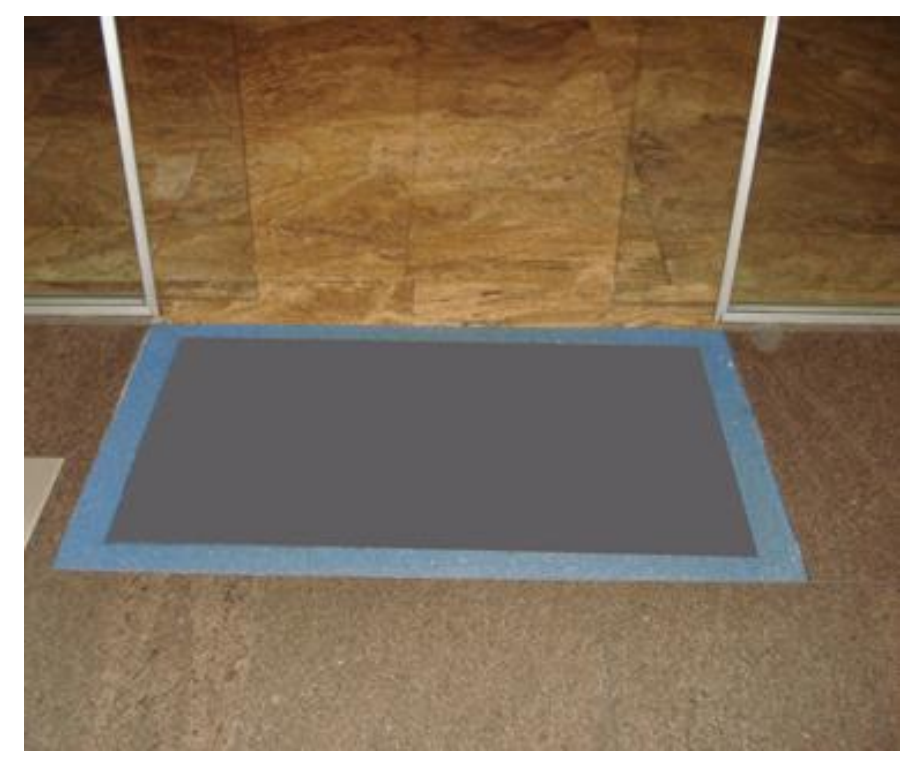

\section{Considerações finais:}

Com base no estudo feito, verificou-se a importância da avaliação das condições de acessibilidade e de mobilidade hospitalar.

Por meio dos instrumentos aplicados, os aspectos identificados pelos usuários durante as entrevistas foram os mesmos verificados pela pesquisadora durante a aplicação dos diversos instrumentos relatados pela equipe de engenharia do local. Fato confirmado 


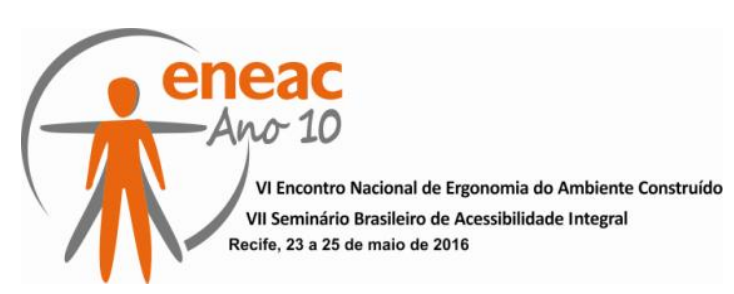

pelos demais instrumentos que evidenciaram que grande parte dos usuários, embora com algumas ressalvas, encontram-se satisfeitos com o local de trabalho.

Embora os pontos negativos do estudo tenham sido demostrados, com o objetivo de repará-los ou, minimizá-los, nenhum item obteve desempenho insatisfatório no questionário aplicado, tendo a maioria recebido pontuação entre muito bom e bom.

Verificou-se a importância da junção dos métodos para a avaliação da acessibilidade e mobilidade hospitalar, pois assim foram levantadas as informações necessárias para se completar uma análise e que a participação dos usuários é de suma importância para a elaboração de um diagnóstico.

Recomenda-se que continuem estudos na área de avaliação hospitalar em relação à acessibilidade e mobilidade, já que não há uma literatura extensa na área.

\section{Referências:}

ABATE, T. P.; KOWALTOWSKI, D.C.C.K.; ONO, Rosaria. Pressupostos teóricos da deficiência relacionados à acessibilidade e ao desenho universal. In: $V$ Encontro Nacional de Ergonomia do Ambiente Construído e VI Seminário Brasileiro de Acessibilidade Integral, Rio de Janeiro. 2014.

ASSOCIAÇÃO BRASILEIRA DE NORMAS TÉCNICAS- ABNT NBR 9050. Acessibilidade a edificações, mobiliário, espaços e equipamentos urbanos. Rio de Janeiro, 2004. 97p.

BRASIL. Ministério da Saúde. Agência Nacional de Vigilância Sanitária. Resolução. Regulamento técnico para planejamento, programação, elaboração e avaliação de projetos físicos de estabelecimentos assistenciais de saúde. Resolução - RDC 50 de 21.02.2002, Brasília, 2002.

CORRÊA, A. R. ANTUNES; J. R. P. MERINO; E. A. D. Estudo ergonômico de acessibilidade para a população idosa: o caso do jardim botânico de São Paulo. FISIONET, 2004. Disponível em:<www.fisionet.com.br/monografias_id.asp?id=1622> Acesso em: agosto, 2013.

GONÇALVEZ, A. Centros para idosos fecha as portas em SP. Estadão de São Paulo, São Paulo, 11 jul. 2009. Vida \& Estilo. Disponível em < http://vidaestilo.estadao.com.br/noticias/geral,centro-para-idosos-fecha-as-portas-em-sp,401481>

MACHADO, E. S. et al. Uma Reflexão Sobre Métodos Utilizados em APO: Estudo de Caso da Creche Edson Luiz- RJ. Anais do XII ENTAC, 2008. Disponível em <http://www.gae.fau.ufrj.br/arq_pdf/artigos/Giselle\%20Arteiro\%20Nielsen\%20Azevedo/ENTA C_CRECHE\%20EDSON\%20LUIZ_2008.pdf>. Acessado em 07 de janeiro de 2012.

MILANI, D. O quarto e o banheiro do idoso: estudo, análise e recomendações para o espaço do usuário residente em instituição de longa permanência; Dissertação de Mestrado apresentada à FAUUSP, São Paulo, SP, 2014.

ORNSTEIN, S.; ROMÉRO, M. Avaliação Pós-Ocupação (APO) do Ambiente Construído. São Paulo: Studio Nobel, 1992. 221p.

SAMPAIO, A. V. C. F. Arquitetura hospitalar: projetos ambientalmente sustentáveis, conforto e qualidade - proposta de um instrumento de avaliação. Tese de Doutorado. Faculdade de Arquitetura e Urbanismo da Universidade de São Paulo- FAU-USP. São Paulo, 2005.

SCARINGELLA, R. S. A Crise na Mobilidade Urbana em São Paulo. São Paulo Perspec. vol.15 no. São Paulo Jan./Mar. 2001. Disponível em: http://www.scielo.br/scielo.php?pid=S0102-88392001000100007\&script=sci_arttext. 


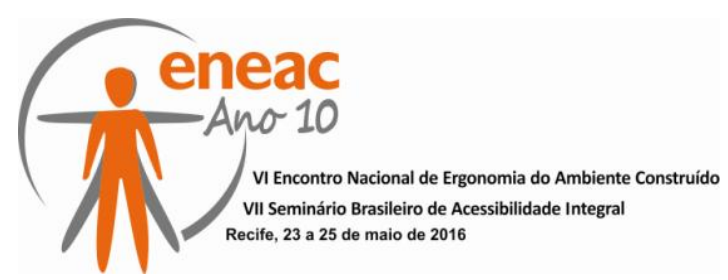

VIANNA J.; VIERA, E. Passeios, Calçadas e Infraestruturas para o Tráfego de Pedestres em São Paulo. Dissertação de Mestrado. Faculdade de Arquitetura e Urbanismo da Universidade de São Paulo- FAU-USP. São Paulo, 2000. 